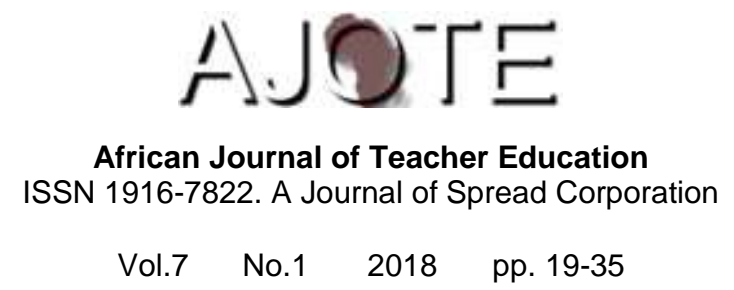

\title{
Relationship between University of Malawi Selection Policy and Entrance of Education Graduates into the Teaching Profession
}

\author{
Wanangwa Wanyasulu Nyirenda Chikazinga, \\ University of Malawi, \\ Kamuzu College of Nursing \\ Richard Walibwe Nyirongo, and Bob Wajizigha Chulu \\ University of Malawi, Chancellor College
}

\begin{abstract}
Many stakeholders have attributed the decisions of education graduates who decline to enter the teaching profession after graduation, to the University of Malawi selection policy, and have called for the abolition of redirecting students to courses other than their choices. The purpose of this study was to measure the relationship between the University of Malawi selection 're-direction policy' and 'entrance of education graduates into the teaching profession'. Cross-section data were collected from the total population of education graduates from the University of Malawi, Chancellor College from 2005 to $2009(\mathrm{n}=760)$, through document analysis and structured interviews. Using the $\chi 2$ test, the calculated $\chi^{2}(1 \mathrm{df})$ was $3.265, \mathrm{p}=0.071$ denoting that the university selection policy and entrance of education graduates into the teaching profession were independent. The study concluded that education graduates entering or declining to enter the teaching profession after graduation did not depend on whether they chose or were redirected to education during their university selection.
\end{abstract}

Keywords: Teacher recruitment, teacher wastage, entrance into the teaching profession, selection/admission policy 


\section{Background to the Study}

The Malawi secondary education system is beset with a huge shortage of qualified secondary school teachers. Mulkeen (2010) found that 61.5 percent of secondary school teachers were qualified as

primary school teachers and could be teaching in primary schools. Studies have shown that among the major contributors to secondary school teacher shortages in Malawi is teacher wastage; "education graduates declining to take up the teaching job after graduating as teachers" (Chikazinga, Chulu and Nyirongo, 2014). Research evidence has shown that the completion of a teaching course is not always a positive predictor for entrance into the teaching profession (Rots, Aelterman, Vlerick \& Vermeulen, 2007). A study on teachers in six Anglophone Africa countries including Malawi found that the entry to teacher training does not necessarily reflect either perceived availability of teacher jobs or the desire to work as teachers. As a result, many people could be trained as teachers, but later decline to enter the teaching profession after graduation, (Mulkeen, 2010). It is not clear what drives the decision of education graduates to decline to enter the teaching profession after graduating as teacher when Malawi as a country continues to experience the shortage of qualified secondary teachers. However, some education stakeholders in Malawi have suggested that the University of Malawi selection policy greatly contributes to such decisions. Yet no study has been conducted to render empirical evidence to such claims. This provided the impetus for this study to empirically examine whether there is any relationship between the University of Malawi selection/admission policy and the education graduates entrance decisions into the teaching profession.

Selection to the University of Malawi is based on the equitable access policy and merit computed from the aggregate score at Malawi School Certificate Examinations (MSCE) or 'O' level equivalent examination. The University of Malawi just like other universities provide for students to make choices for the kind of programmes that they would prefer to pursue when selected. At the time of conducting this study students were given three options; first choice, second choice and third choice. The provision for a range of choices emanated from the fact that the university admits meager number of students approximately $1 \%$ of those that sit for Malawi School Certificate Examinations. The selection policy states that "candidates will be placed in various faculties using specific faculty requirements, bearing in mind the candidates' choice of programmes or otherwise redirected to other programmes when the candidates do not compete successfully in programmes of their choice" (University of Malawi, 2010). This entails that those students who are unable to make it into their first choice of programme, but still qualify for selection (i.e. they are within the cut-off point) are selected 
for the second choice and finally the third choice. However, if some students meet the cut-off point but all their three choice programmes are full, they are re-directed to any other programme which is not yet filled up (Nampota, 2009). Most students selected to universities or colleges through the 'redirection policy' are likely to be admitted to education programmes because relatively few students who perform extremely well during MSCE or ' $\mathrm{O}$ ' level examinations opt for education as they make choices for selection. Kadzamira (2005) found that teacher training programmes at both primary and secondary levels fail to attract better qualified students into teaching in Malawi. It seems that academically talented individuals prefer to pursue high status, financially rewarding careers in areas such as medicine, law, engineering, economics, or business studies and not education. In some cases, it seems they are also discouraged from pursuing the teaching career because of the perception that teacher education programmes 'lack rigor' and are reserved for those individuals who cannot make it in any other course of study. Consequently, many education programmes absorb secondary school leavers that fail to compete successfully and get places in other university's programmes (Mulkeen, 2010).

Nampota (2009) shows that during the University of Malawi selection exercise of 2006, fifty students were selected into education science programme at Chancellor College. But out of the fifty only two had made education science (ESC) as their choice and this choice was third. The vast majority (48) did not choose education science anywhere but because all the three programmes they were interested in were full, they were redirected into education science. Nampota (2009) further, commented on the weakness of redirecting students to programmes other than their choices. She argued that the redirected students may not have commitment to a profession they did not choose. Chimwenje (2003) also suggested that the number of graduate secondary school teachers that never enter or remain in the teaching profession in Malawi should be higher because most of these students choose other types of training courses other than education but are redirected to train as secondary teachers against their wish.

\section{Problem Statement}

Many stakeholders have attributed the decision of education graduates to decline to enter the teaching profession "teacher wastage" to the University of Malawi selection "re-direction" policy. The most compelling argument about teacher wastage advanced in different fora is that when recruits have little initial commitment to teaching they can hardly enter or remain in the teaching profession, and in more 
extreme cases, if talented individuals happen to join teaching by accident they are likely to quit at their first opportunity (Chimwenje, 2003; Nampota, 2009). Stakeholders have therefore made calls for the University of Malawi, to stop redirecting students to programmes other than their choice during admission. However, no empirical study has ever been conducted to explore whether students redirected to education courses in the University of Malawi enter or decline to enter the teaching profession after graduation. This gave a thrust to this study to answer the question "Is there a relationship between the University of Malawi selection "re-direction" policy and entrance of education graduates into the teaching profession?

\section{Purpose of the Study}

The purpose of this study was to measure the relationship between the University of Malawi selection 're-direction' policy and entrance of education graduates into the teaching profession. In order to achieve this purpose, the study answered three research questions:

1. What choice of study programme did education graduates make during university admission?

2. To what extent did the education graduates enter the teaching profession after graduation?

3. What is the relationship between the University of Malawi admission policy and entrance of education graduates into the teaching profession?

\section{Significance of the Study}

The study will provide feedback to policy makers, educationists and other stakeholders regarding the impact of the University of Malawi selection 'redirection' policies on the wastage of education graduates. It would also help the University of Malawi to re-examine the current admission criteria into its education programmes. It will also add to the body of knowledge on admission policies and education graduates entrance and retention in the education system.

\section{Theoretical Perspective}

Rots, Aelterman, Devos, and Vlerick (2010) developed a model which attempts to explain the teacher education graduates decision whether or not to enter the teaching profession upon graduation. The model distinguishes between, on the one hand, teacher education experiences, initial motivation for teaching, integration into teaching, teaching commitment and, on the other hand, external influences as key variables that influence the intention whether or not to enter the teaching profession. According to the model trainees who start teacher education because they want to work as teachers and those who report higher teaching commitment at the end of teacher education are more likely to show higher 
intention to enter teaching at the time of their graduation (Rots, Aelterman, Vlerick, and Vermeulen, 2007; Rots and Aelterman, 2008, 2009 and Rots, et al. 2010). Similarly, nearly graduated teacher trainees with higher level of teacher efficacy, more extended professional orientation and stronger learner-oriented beliefs are suggested to show higher teaching commitment and subsequently a stronger intention to enter teaching. Rots and Aelterman (2009) further show that faculty support, mentor support and teacher education preparation have a positive indirect association with intention to enter teaching, while factors external to the teaching profession tend to be negatively related to the intention to enter the teaching profession. Two variables from the model namely 'initial motivation for teaching' and 'teaching commitment' were of particular importance to this study. Notwithstanding the exclusion of the other variables, 'initial motivation for teaching' which in the context of this study can be depicted by the choice of programme students choose for admission into the university, is shown to have an influence on both the commitment to teaching as a career and the decision of education graduates whether or not to enter the teaching profession. This suggests that there must be a strong positive relationship between admission policy and entrance into the teaching profession.

\section{Motives for choosing teaching as a career}

Studies on motives for choosing teaching as a career indicate various reasons and show that individuals recruited to teacher education hold personal and sometimes idiosyncratic motives about the teaching profession which have a bearing on whether these individuals become classroom teachers or join the ranks of 'competent nomads' (Bastick, 1999; Mtika and Gates, 2010). Three categories of motives have been identified to affect students' choice of the teaching profession namely; altruistic, intrinsic and extrinsic factors (Young, 1995; Moran, Kilpatrick, Abbot, Dallat, and Mc Clane, 2001; Wang and Fwu, 2001; Khoh, Ling, Ch'ng, and Chuan, 2005). The altruistic motive is couched in terms that consider teaching as a desire to help children and contribute to society, while intrinsic factors associate interest in teaching with teaching itself such as the activity of teaching and interest in using knowledge and expertise of the subject. The extrinsic motive includes material rewards attached to the teaching profession such as salary, stability and working conditions (Chan, 2006; Kizilaslan, 2010). Scholars who have examined the motives for choosing teaching as a career among both pre-service and inservice undergraduate student teachers and those enrolled in the postgraduate certificate in education programs in the United States of America, United Kingdom, Greece, Turkey and Australia have shown that such students are mostly motivated by idealistic and altruistic factors (Young, 1995; Doliopoulou, 
1995; Papanastasiou and Papanastasiou, 1997; Richardson and Watt, 2006; Kizilaslan, 2010). Similar studies conducted in Israel and in Asian countries of Singapore, Taiwan, Malaysia, and Hongkong have reported related findings (Wang and Fwu 2000; Khoh, Ling, Ch'ng and Chuan, 2002; Chan, 2005; Keow, 2005; Ilaiyan and Zidan, 2005). Doliopoulou's (1995) research resulted in a profound finding that in Greece, early childhood department was the first choice [of teacher education program] of several of the kindergarten teachers $(43 \%)$ who participated in the study and among the choices of many of them (93\%). This suggests that pre-service teachers motivated by intrinsic/altruistic motives are more likely to indicate teacher education as their first choice or among their choices for entrance into the university/college.

In most developing countries, it has been shown that student teachers tend to place a high value on extrinsic factors. Bista (2006) found that in Nepal, for $30 \%$ of the 416 female teachers in his study, joining teaching was an economic compulsion. Only $20 \%$ stated that teaching gave them a forum for doing social work while some $18 \%$ happened to train as teachers after they were rejected in their efforts other than teaching. Young (1995) for Brunei Darussalam and Bastick (1999) for Jamaica, also highlight the fact that extrinsic motives were the main determinants for trainees to choose teaching. The study in Brunei Darussalam found that almost $15 \%$ of the trainees who entered teaching did so as a last resort due to failure to enter another profession while $12 \%$ were influenced by others to choose teaching. Mtika and Gates (2010) found that among secondary teacher trainees in Malawi, some trainees never considered teaching as a career option but joined teaching due to failure to make it to university to study other courses they had wished for. Still other trainees showed an intention to use teaching profession as a means to get somewhere else in their career pursuit - 'a springboard to a career elsewhere'. However, the study also found that for some trainees, teaching was the only profession they had ever wanted to pursue - 'teaching as a vocation' - which aligns with both altruistic and intrinsic notions. Interestingly, only three out of the fourteen trainee teachers who participated in the study cited entering teacher training course because teaching was a vocation to them (Mtika and Gates, 2010). These studies show that unlike in developed countries where teacher trainees cite intrinsic or altruistic reasons, in most developing countries student teachers attribute instrumental reasons related to external motives to their choice of teaching as a career. Studies from developing countries also suggest that not all student teachers purposefully enter teacher education "entry by design". For some, entry into teacher education happens by accident - "an unintended happening". It would not be surprising if such students do not enter teaching after graduating as teachers. 


\section{Commitment to the teaching career}

Few studies have also explored the prospective teacher commitment to the teaching career. Coladarci (1992, p.362) define commitment to teaching as the "teachers' psychological attachment to the teaching profession". Studies in Taiwan, Hong Kong and United States of America have shown that there is a relationship between the motivation for choosing teaching and the degree of commitment to the career (Wang and Fwu, 2001; Chan, 2006). These studies found that teacher trainees who are more committed to teaching regard the teaching career as a calling, display more enthusiasm and place less emphasis on extrinsic motives such as salary and working conditions. In addition, the studies predicted that where teachers are not committed to the teaching profession, most of these teachers would likely decline to enter or remain in the teaching profession. However, some studies have also shown that some trainees that enter teacher education "by accident" or that were "motivated by extrinsic factors" can sometimes reconsider their initial motive due to the teacher education experiences and become committed to the profession after graduation (Rots, et al. 2010).

\section{Entrance into the teaching profession}

Cockburn and Haydn (2004) argued that despite teaching being established as a graduate career for many generations in most developed countries, the number of graduates entering the teaching profession has declined in recent years raising a big concern about wastage from the profession. A research report "Enhancing the teaching profession" in United States of America revealed that the growing numbers of students indicated interest and entered teacher preparation programmes in various universities and colleges. However, upon graduation many of these students especially those in high demand fields decided not to apply for teaching jobs or did not accept positions when they were offered (Hirsch, Rodriquez, Curran and Laine, 2001). Bullard's (1998) synthesis of research studies on teacher recruitment, retention, preparation and professional development in California further noted that the numbers of people who joined teacher training and became credentialed were a fraction of those interested in teaching. Those who wanted to enter teacher training programme often did not find slots. As a result, more than $25 \%$ of the programme openings were taken by people who did not enter the teaching profession after graduation while many aspiring teachers were denied entry. This seems to portray that the decision by graduates not to join teaching in California largely emanated from problems with the selection policies to teacher education. Purcell, Davies and Elias (2005) using data from two national surveys of United Kingdom graduates of 1995 and 1999 at 38 UK Higher 
Education Institutions examined the early career paths of 1999 graduates qualified to teach either by the completion of an undergraduate education degree resulting in Qualified Teacher Status (QTS), a postgraduate certificate in education (PGCE) or by some other routes. Findings from this study revealed that on average $20 \%$ of Bed/BA/BSc (QTS) graduates and $39 \%$ of PGCE holders never entered the profession after completion of teacher education. Similarly, findings from the class of ' 99 survey revealed that 40 percent of women who had graduated with a Bed/BA/BSc (QTS) were not teaching at the time of the survey (Purcell, et. al. 2005). These studies therefore, show that the tendency of people declining to enter the teaching profession after being trained as teachers happens in many countries even though the magnitude might be different, and that the critical point where a significant number of potential teachers are lost is between the completion of teacher training and the entry to the profession.

In Sub-Sahara Africa, Mulkeen's (2010) synthesis of research data from case studies on teachers in eight Anglophone Africa countries (Malawi, Uganda, Zambia, Gambia, Lesotho, Liberia, Zanzibar and Eritrea) found that in some countries many of the teachers who were trained never actually entered the teaching profession. A case study in Zambia shows that 1,017 teachers with degrees were working in schools in 2005, yet the University of Zambia had an output of over 400 graduate teachers each year for the past five years and (431 in 2006). Mulkeen concluded that most of the graduates were either not entering the teaching profession or not staying in it very long. A related study in Liberia indicates that the University of Liberia graduated 13 teachers with degrees in primary education and 23 with degrees in secondary education in 2007. It is reported that most of these were existing teachers who had undergone the degree course on study leave from the post. However, despite a system requiring students to sign bonds committing them to work in schools, very few returned to teaching once training was completed. The synthesis concluded that accurate information on graduate teacher that decline to enter the teaching profession after graduation was rarely available in all the countries under study despite indications that it is a significant problem in some countries.

\section{Study Design}

The study followed the quantitative approach and adopted the cross-sectional design. Entrance of education graduates into the teaching profession was investigated among different cohorts of education graduates from the University of Malawi, Chancellor College from 2005 to 2009 but data were collected at a single point in time although the actual time took approximately six months to complete 
data collection. The study used a census approach where data were collected on the entire population of education graduates from 2005 to 2009. A total of 578 education graduates from Chancellor College from 2005 to 2009 formed the units of analysis. The focus on education graduates from the University of Malawi, Chancellor college was because the University of Malawi is the oldest and main university of the country and Chancellor College is one of its constituent colleges housing the oldest and main faculty of education which is responsible for training the majority of graduate secondary teachers in Malawi.

\section{Data Collection}

The study reviewed administrative documents from the University of Malawi, and Malawi Ministry of Education to obtain data. The decision to undertake secondary data analysis was largely determined by the nature of the study objectives. Categorical analysis, a more systematic analysis based on categories constructed before the commencement of the study, was used to review the documents (Sarantakos 2005). There were four sets of pre-determined categories namely:

1) Graduates that chose education,

2) Graduates that were redirected to education,

3) Graduates that entered the teaching profession after graduation; and

4) Graduates that declined to enter the teaching profession after graduation.

The study reviewed the University of Malawi, selection books (of 2000, 2002 to 2004) and education graduates lists of 2005 to 2009 to collect data on the choices of programme of study indicated by the education graduates during their university selection to find out those who put education among their choices (chose education) and those who did not indicate education among all their three choices (redirected to education). The use of documents from the University of Malawi central office was intended to avoid self-report which could have produced unreliable data due to memory decay or memory distortion and the social desirability effect, where most people would want to indicate that they did not intend to train as teachers but were just redirected during the university admission/selection. The study also reviewed the Malawi Ministry of Education staff returns using a validated list of education graduates from (2005 to 2009) to collect data on graduate entrance into the teaching profession. Since staff returns are meant to cover all teachers in the public system, it provided the study with the widest breadth of the data i.e. covering the national population of public secondary school teachers. The pre-determined variables which were supposed to correlate on both documents 
were the First name, Surname, Academic qualification (Bachelor of Education- abbreviated as BEd), College where trained (Chancellor College-abbreviated as Chanco) and Sex. In addition, Year of first Appointment was supposed to be in exactitude with year of graduation. The researcher also conducted structured interviews with education graduates who could not be traced using staff returns to find out whether they joined teaching immediately after their graduation or not.

\section{Data Analysis}

The data were entered and analyzed through the statistical package for social scientists (SPSS 16.0). Descriptive statistics particularly frequencies and percentages were generated to summarize the data as well as answer the first two research questions. The study computed the chi-square $\left(\chi^{2}\right)$ test of independence to determine whether the University of Malawi selection policy and entrance of education graduates in the teaching profession were associated in order to answer the third research question.

\section{Validity and reliability}

To address the issues of validity the study ensured objectivity by guaranteeing the total independence of the researcher through the use of structured instruments. The variables and constructs measured in the study were also delineated from carefully examined pre-existing theories and research findings to enhance the quality of the measures. The study further ensured that the content of the secondary data was appropriate, comprehensive and thoroughly covered the intended variables without which all dubious secondary data were discarded. Similarly, the statistical procedures applied to the data and assumptions required for their application were complied with to avoid conclusions which can falsely influence practice and further research. In terms of reliability, the secondary and primary data collected by the study to answer the research questions of the study were factual, (i.e. either education graduate 'chose education' or 'were redirected' and 'entered the profession' after graduation or 'declined') denoting that the results of the study were amenable to replication.

\section{Ethical consideration}

Informed consent was sought from the institutions involved in this study, namely Malawi Ministry of Education, the six education divisions of Malawi, University of Malawi central office and Chancellor College. This allowed the study to access the official records from which secondary data were generated. Similarly, prior to interviews with education graduates who could not be traced on secondary data sources, all relevant information about the researcher and the study in general were 
presented to the respondents to gain their informed consent and that the right to withdraw was also guaranteed. The official records and data collected by the study were held with utmost confidentiality and the respondents and personnel from institutions involved in the study were informed that the study by its nature did not expose them to any risk or harm.

\section{Limitations of the study}

The study succumbed to the issue of documents selective survival bias, since the entrance examination results book of 2001 was not found at the University Office. As a result, the choices of programme of study for education graduates of 2006 were not collected and accordingly omitted in the analysis of data on the third research question. The study also did not examine other factors that influence the education graduates entrance into the teaching profession, as well as the impact of the University of Malawi admission/selection policy on the retention and commitment of the redirected education graduate teachers to the teaching profession. This could have been ideal, but it was beyond the scope of this study to examine such issues.

\section{Results of the Study}

\section{Choice of study programme during university admission/selection}

The figure 1 below shows the choice of study programme made by education graduates during their university admission. While $46 \%$ of the education graduates from 2005 to 2009 chose education as one of the choices to be considered for admission into the university, the majority of education graduates (54\%) did not indicate education among all their three choices but were redirected to education by the university.

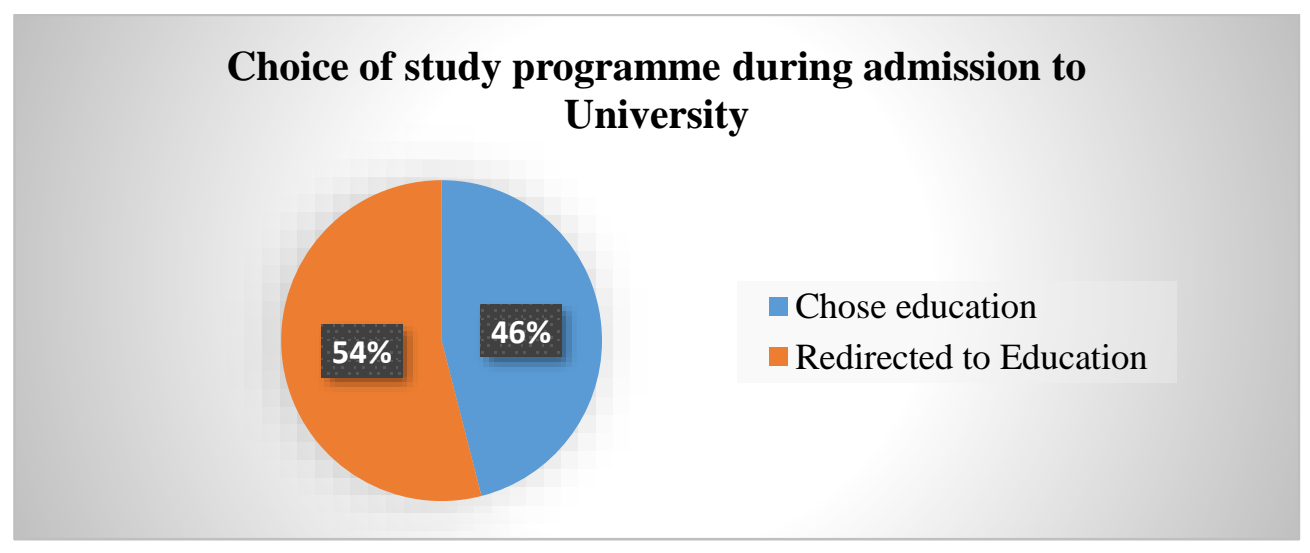

Figure 1: Choice of study programme during the University of Malawi admission 


\section{Education graduates entrance into the teaching profession}

The study found that in 2005, 84.8.6\% of the education graduates from University of Malawi, Chancellor College entered the teaching profession after graduation while $15.2 \%$ declined. In 2006, $84.7 \%$ entered while $15.3 \%$ declined, in $2007,92.5 \%$ entered while $7.5 \%$ declined. $88.2 \%$ of the education graduates entered the teaching profession in 2008 while $11.8 \%$ declined, and $88.6 \%$ entered in 2009 while $11.4 \%$ declined (figure 2). This shows that from 2005 to 2009, 87.8\% of the education graduates entered the teaching profession after graduation while $12.2 \%$ declined. The study further found that the majority of education graduates who entered the teaching profession were $46.4 \%$ of those who did not choose education (redirected to education) during university admission, whereas slightly fewer graduates that chose education entered the teaching profession (42.6\%).

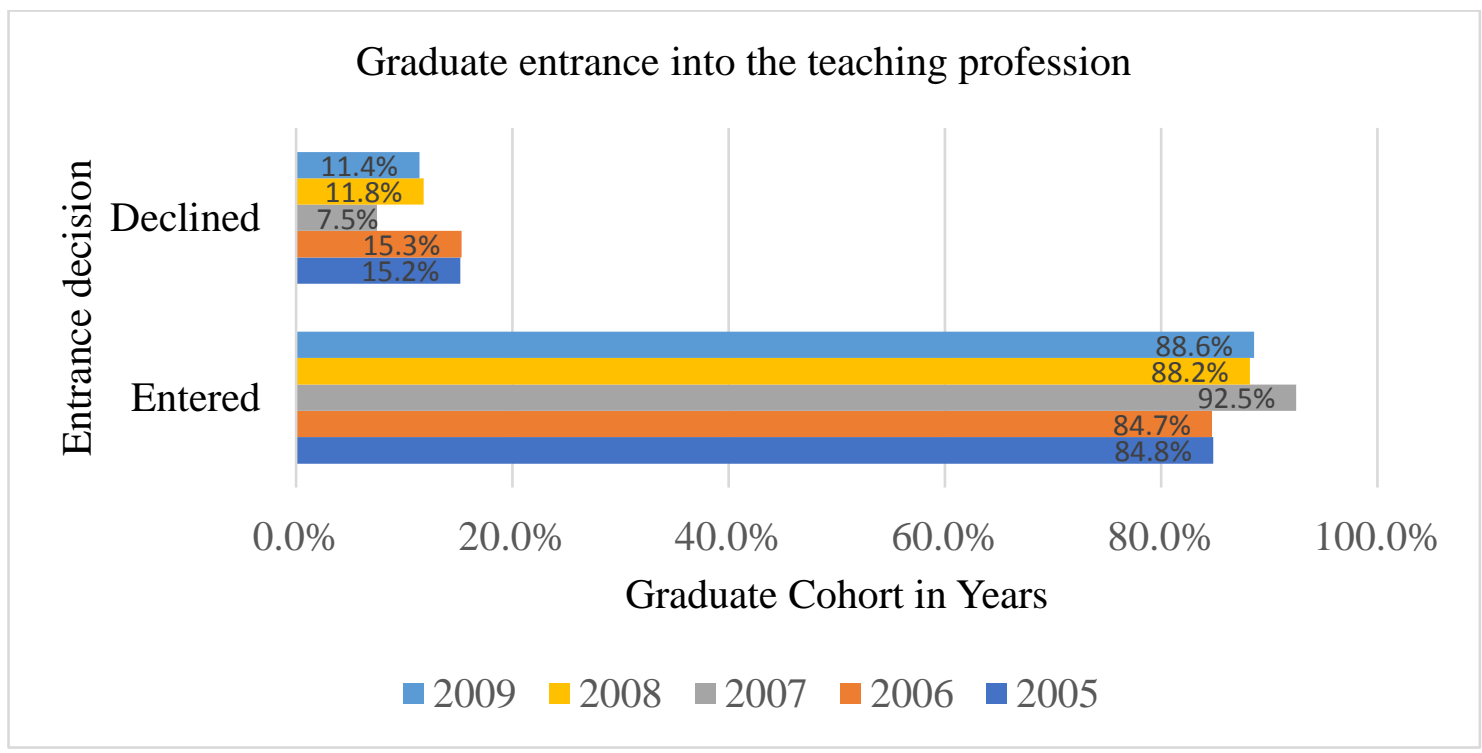

Figure 2: Graduates entrance into the teaching profession

\section{Relationship between university selection policy and entrance into the teaching profession}

To examine whether the two variables "university selection policy" and "entrance into the teaching profession" were associated the study computed the $\chi^{2}$ test of Independence using the $2 \times 2$ contingency table of observed and expected frequencies (Table 1). 
Table 1: (2x2) Contingency table for Entrance into Teaching and the University Selection Policy

\begin{tabular}{|l|l|l|l|}
\cline { 2 - 3 } \multicolumn{1}{c|}{} & $\begin{array}{l}\text { Entrance into Teaching } \\
\text { Profession }\end{array}$ & \\
\hline $\begin{array}{l}\text { University Selection } \\
\text { Policy }\end{array}$ & Declined & Entered & Total \\
\hline Redirected & $\mathbf{4 1 ( 3 4 . 2 )}$ & $\mathbf{2 6 8 ( 2 7 4 . 8 )}$ & $\mathbf{3 0 9}$ \\
\hline Chose Education & $\mathbf{2 3 ( 2 9 . 8 )}$ & $\mathbf{2 4 6}(\mathbf{2 3 9 . 2 )}$ & $\mathbf{2 6 9}$ \\
\hline Marginal Total & $\mathbf{6 4}$ & $\mathbf{5 1 4}$ & $\mathbf{5 7 8}$ \\
\hline
\end{tabular}

The study found that the computed $\chi^{2}$ (1df) was $3.265, p=0.071$ and did not exceed the critical value of $\chi^{2} 0.05(1 \mathrm{df})=3.84$. It was concluded that whether an education graduate entered or declined to enter the teaching profession (Entrance into teaching) did not depend on whether they chose or were redirected to education (Selection Policy).

\section{Discussion}

The study has shown that fewer education graduates from University of Malawi Chancellor College from 2005 to 2009 (46\%) chose education while the majority of the education graduates (54\%) were redirected to education as they did not indicate education among all their three choices during university admission. This conforms to findings by Nampota (2009) and Mtika and Gates (2010) that prospective secondary school teachers who do not compete successfully in the programmes of their choice but still qualify for selection during university admission are sometimes simply redirected to study education at the University of Malawi against their wish. This implies that entry into teacher education for the $54 \%$ of the education graduates in this study was not by design, rather it was an unintended happening. These are the type of education graduates or prospective teachers that the studies reviewed in this paper describe as having little or no initial motivation and commitment to the teaching profession and predict that they are less likely to enter the teaching profession after graduation (Chan, 2006; Oplatka, 2007).

The study further found that $87.8 \%$ of the education graduates from 2005 to 2009 entered the teaching profession after graduation while $12.2 \%$ declined. Surprisingly, among the education graduates who entered the teaching profession were $46.4 \%$ of those who were redirected to education compared to only $42.6 \%$ of the graduates that chose education during university admission. It is not clear what compelled education graduates who were 'redirected to education' to consider entering the teaching profession more than those who chose education during university admission. However, a 
plausible explanation posited by some studies is that trainees that enter teacher education "by accident" or or were "motivated by extrinsic factors" can sometimes reconsider their initial motive due to the teacher education experiences and become committed to the profession after graduation (Stokes, 2007). That is the faculty support, mentor support and teacher education preparation might have enhanced their sense of teacher efficacy (Rots, et. al. 2010).

Most importantly, the study has shown that the wastage rate of education graduates was not associated with the University of Malawi selection policy. That is whether education graduates 'entered' or 'declined to enter' the teaching profession was not related to whether they were 'redirected' or 'chose' education during the university admission or selection. This is contrary to wide speculations and anecdotal reports which attributed the decision by education graduate to decline to enter the teaching profession after graduation (teacher wastage) to the University of Malawi selection "redirected" policy. Basically, redirection to education during university admission signifies "lack of initial motivation and commitment", but the findings of this study contradicted findings reported by most studies which ascertained that education graduates with 'little initial motivation and commitment to teaching' were less likely to join teaching after graduation (Bullard, 1998; Macdonald, 1999). This clearly shows that the positive relationship between 'initial motivation for teaching' and 'entrance into the teaching profession' found by some researchers (Wang and Fwu, 2001; Chang, 2006) was not conclusive in explaining teacher wastage. This suggest that the initial motivation hardly accounted for the entrance decision of education graduates from Chancellor College which begs to seek the role of other factors.

\section{Conclusion}

The findings of this study have shown that the majority of education graduates from the University of Malawi, Chancellor College from 2005 to 2009, were redirected to study education confirming findings of other studies that in developing countries not all student teachers purposely enter teaching education - 'entry by design'- as entry into teacher education happen by accident, 'unintended happening' for some. The study further revealed that the University of Malawi admission/selection policy and entrance of education graduates into the teaching profession were independent of each other. This is contrary to wide speculations and anecdotal reports which attribute the education graduates' decision to decline to enter the teaching profession to the University of Malawi selection "redirected" policy. Thus, this study provides empirical support to the University of Malawi selection 'redirected' policy. Considering that few talented people opt for education as they make choices during university admission, their 
redirection to study education does not have any significant association with declining to enter the teaching profession after graduation. Therefore, if necessary the 'redirected' policy should continue. However, there is need for further studies to investigate factors that drive the decision of education graduates to decline to enter the teaching profession.

\section{References}

Bastick, T. (2000). Why teacher trainees choose the teaching profession: comparing trainees in Metropolitan and developing countries. International Review of Education 46 (4), 343-349.

Bastick, T. (1999). A three factor model to resolve the controversies of why trainees are motivated to choose the teaching profession. Paper presented at the $5^{\text {th }}$ Biennial Cross Campus Conference in Education “Controversies in Education”. St. Augustine, Trinidad: University of West Indies:

Bista, M.B. (2006). Status of female teachers in Nepal. Kathmandu, Nepal: UNESCO Publication Bullard, C. (1998). Qualified teachers for all California students: Current issues in recruitment, retention, preparation and professional development. California: California Research Bureau.

Chang, K.W. (2006). In-service teacher perceptions of teaching as a career; Motive and commitment in teaching. Paper presented at the AARE International education research conference, University of Western Sydney, Parramatta Campus, Sydney, Australia.

Chikazinga, W.W.N., Chulu, B.W. and Nyirongo, R.W. (2014). Wastage rate of education graduates from University of Malawi, Chancellor College from 2005 to 2009. Educational Planning. 21, (4), 5-24

Chimwenje, D. (2003). Secondary teacher education in Malawi. Paper presented at an International seminar on teacher education held on 27-28 march, at Chancellor College, Zomba.

Doliopoulou, E. (1995). The motives for the selection of the teaching profession by future Kindergarten teachers and the factors which form their later opinion of their Profession. International Journal of Early Childhood. 27, 28-33.

Hirsch, E. et al., (2001). Recruitment: staffing classrooms with quality teachers. Report of the SHEEO project "Enhancing the teaching profession: The importance of mobility to recruitment and retention”. Denver, USA: State Higher Education Executive Officers (SHEEO).

Ilaiyan, S. and Zidan, R. (2005). Motives for selecting the teaching profession among teaching trainees in the Arab sector in Israel. Haifa: The Arab academic college of education. 
Kadzamira, E.C. (2005). Teacher motivation and incentives in Malawi. Zomba: Centre for education research and training.

Keow, C.L. (2005). Motives for choosing the teaching profession; Voices of pre-service teachers from Malaysia. Maktab perguruan ipoh perak.

Khoh, L.S., Ling, L.E., Ch'ng, A. and Chuan, G.K. (2005). Student teachers reasons for choosing teaching as a career. Nanyang, Singapore: National institute of education, Nanyang Technological University.

Kizilaslan, I. (2010). Student teachers' motives for choosing the ELT profession: A

Quantitative description. Paper presented at an international conference on new Trends in education and their implications 11-13 November, Antalya-Turkey

Macdonald, D. (1999). Teacher attrition: A review of literature. Teaching and Teacher Education. 15, 835-848

Moran, A. Kilpatrick, R. Abbot, L. Dallat, J \& Mc Clane, B (2001). Training to teach: Motivating factors and implications for recruitment. Evaluation and Research in Education.15 (1), 17-32.

Mtika, P and Gates, P. (2010). What do secondary trainee teachers say about teaching as a profession of their choice in Malawi. Teaching and Teacher Education. 30, 1-10.

Mulkeen, A. (2010). Teachers in Anglophone Africa: Issues in teacher supply, training and management. Washington DC: The World Bank.

Nampota, D.C. (2009). Training teachers for secondary mathematics and science: The challenge facing University of Malawi. Zomba: Chancellor College.

Papanastasiou, C. and Papanastasiou, E. (1997). Factors that influence students to become teachers. Educational Research and Evaluation 3(4), 305-316.

Richardson, P.W. and Watt, H.M.G. (2006). Who chooses teaching and why? Profiling characteristics and motivation across three Australian universities. Asia-Pacific Journal of Teacher Education, 34 (1), 27-56.

Rots, I and Aelterman, A (2009). Teacher education graduates' entrance into the teaching profession. Development and test of a model. European journal of Psychology of education, 14 (4), 453-471. , (2008). Teacher training for secondary education and graduates entrance into the teaching profession. Education Studies 34, 399-417.

, Vlerick, P., \& Vermeulen, K. (2007). Teacher education graduates' teaching commitment and entrance into the teaching profession. Teaching and Teacher Education, 23, 543-556. 
, Devos, G \& Vlerick, P. (2010). Teacher education and the choice to enter the teaching profession: A prospective study. Teaching and Teacher Education, 26, 1619-1629

Oplatka, I. (2007). The context and profile of teachers in developing countries in the last decade: A revealing discussion for further investigation. International Journal of Education Management. 21, (6), 476-490. Accessed at http://www.emeraldinsight.com/0951-354X.htm

Stokes, A.R. (2007). The challenge of attracting and keeping quality teachers in Catholic Schools in Australia. Economic working paper series: Greenacre Educational Publication (GEP). University of Malawi (2010). University of Malawi programmes and entry requirements. Zomba, University Central Office: UNIMA.

Wang, H.H and Fwu, B.J. (2001). Why teach; the motivation and commitment of graduate students of a teacher education programme in a research university. Practical National Service Council. ROC (C). 11 (4), 390-400.

Young, B.C.S. (1995). Teacher trainees' motives for entering a teaching career in Brunei Darussalam. Teaching and Teacher Education. 11. (3), 275-280. 